\title{
AVT is involved in the regulation of ion transport in the intestine of the sea bream (Sparus aurata)
}

J.A. Martos-Sitcha ${ }^{1,2,3}$, S.F. Gregório ${ }^{1}$, E.S.M. Carvalho ${ }^{1}$, A.V.M. Canario ${ }^{1}$, D.M. Power ${ }^{1}$, J.M. Mancera ${ }^{2}$, G. Martínez-Rodríguez ${ }^{3} \&$ J. Fuentes ${ }^{1}$

(1) Centre of Marine Sciences (CCMar), CIMAR - Laboratório Associado, Universidade do Algarve, Campus de Gambelas, 8005-139 Faro, Portugal

(2) Departamento de Biología, Facultad de Ciencias del Mar y Ambientales, Universidad de Cádiz, E-11510 Puerto Real (Cádiz), Spain

(3) Instituto de Ciencias Marinas de Andalucía, Consejo Superior Investigaciones Científicas (ICMAN-CSIC), E-11510 Puerto Real (Cádiz), Spain

Running head title: AVT regulates ion balance in fish intestine

Author for correspondence:

Juan Fuentes (jfuentes@ualg.pt)

CCMar, CIMAR - Laboratório Associado,

Universidade do Algarve

Campus de Gambelas,

8005-139 Faro, Portugal 
ABSTRACT

2 The intestine of marine fish plays a crucial role in ion homeostasis by selective processing of 3 ingested fluid. Although arginine vasotocin (AVT) is suggested to play a role in ion 4 regulation in fish, its action in the intestine has not been demonstrated. Thus, the present study 5 investigated in vitro the putative role of AVT in intestinal ion transport in the sea bream 6 (Sparus aurata). A cDNA encoding part of an AVT receptor was isolated and phylogenetic 7 analysis revealed it clustered with the V1a2-type receptor clade. Vla2 transcripts were 8 expressed throughout the gastrointestinal tract, from esophagus to rectum, and were most 9 abundant in the rectum regardless of long-term exposure to external salinities of 12, 35 or 55 10 p.p.t. Basolateral addition of AVT $\left(10^{-6} \mathrm{M}\right)$ to the anterior intestine and rectum of sea bream 11 adapted to 12,35 or 55 p.p.t. mounted in Ussing chambers produced rapid salinity and region 12 dependent responses in short circuit current (Isc), always in the absorptive direction. In 13 addition, AVT stimulation of absorptive Isc conformed to a dose-response curve, with 14 significant threshold effects achieved at $10^{-8} \mathrm{M}$, which corresponds to physiological values of 15 plasma AVT for this species. The effect of AVT on intestinal Isc was insensitive to the CFTR 16 selective inhibitor NPPB $(200 \mu \mathrm{M})$ applied apically, but was completely abolished in the 17 presence of apical bumetanide $(200 \mu \mathrm{M})$. We propose a role for AVT in the regulation of ion 18 absorption in the intestine of the sea bream mediated by an absorptive bumetanide-sensitive 19 mechanism, likely NKCC2.

23 Keywords: osmoregulation, arginine vasotocin, Vla2 receptor, sea bream, salinity, short 24 circuit, water absorption. 


\section{INTRODUCTION}

The intestine of marine fish plays a key role in ion regulation. The ionic disequilibrium of marine fish with their surrounding environment requires high rates of water ingestion (drinking) as part of the osmoregulatory process to compensate the dehydrating effect of seawater in the gills (Evans et al., 2005). In this context, ion assimilation from the ingested fluid is required to drive water absorption, making the role of the intestine vital to maintain extracellular homeostasis. Water absorption seems to rely on $\mathrm{Cl}^{-}$uptake, which is mediated by an apical $\mathrm{Na}^{+} / \mathrm{K}^{+} / 2 \mathrm{Cl}^{-}$co-transporter (Musch et al., 1982) or apical $\mathrm{Cl}^{-} / \mathrm{HCO}_{3}^{-}$anion exchangers (Grosell, 2006, 2011), both mechanisms are active in the sea bream intestine (Carvalho et al., 2012; Gregorio et al., 2013). A basolateral $\mathrm{Na}^{+}, \mathrm{K}^{+}$-ATPase generates the electrogenic potential to facilitate apical $\mathrm{Cl}^{-}$absorption (Ferlazzo et al., 2012). Accordingly, higher intestinal $\mathrm{Na}^{+}, \mathrm{K}^{+}$-ATPase activity is detected in seawater compared to freshwater trout (Fuentes et al., 1997) and is consistent with higher ATPase subunit expression in seawater compared to freshwater eels (Kalujnaia et al., 2007). Arginine vasotocin (AVT) is a peptide secreted from the neurohypophysis of non-mammalian vertebrates, whereas arginine vasopressin (AVP) is the structural and functional counterpart in mammals (Acher, 1993). The AVT/AVP family exerts its endocrine action by binding specific plasma membrane receptors and has diverse physiological actions ranging from behavior, stress, reproduction, and vascular control to osmoregulation (Balment et al., 2006; Goodson, 2008; Kulczykowska, 2007; Mancera et al., 2008). Three AVP receptors (AVPRs) are described in mammals and retain a specific and well-established tissue distribution, e. g. the AVPR type V1a, is associated with vascular smooth muscle; the AVPR V1b, is in pituitary corticotrophs; and the AVPR V2 is in the kidney and linked to renal hydrosmotic actions (Mahlmann et al., 1994; Warne, 2001). In contrast, AVTRs in teleost fish have a broader tissue distribution. Thus, AVTR V1 or V2 subtypes have been described in the central nervous system and in tissues such as gill, kidney, gonads or the gastrointestinal tract (Konno et al., 2009; Lema, 2010).

It seems likely that the prevailing action of the AVT/AVP system is directed to preservation of blood volume and osmolality (Warne et al., 2002). Thus, AVP stimulates for instance tubular $\mathrm{Na}^{+}$transport by activation of $\mathrm{Na}^{+}$channels present in the apical membranes of the kidney tubule (Mordasini et al., 2005; Schafer et al., 1990). Yet, in other epithelia, such as the bronchial epithelium, AVP stimulates $\mathrm{Cl}^{-}$(and the resulting fluid) secretion via an NPPBsensitive, likely CFTR dependent mechanism (Bernard et al., 2005). Other 
electrophysiological studies have demonstrated that AVP alters $\mathrm{NaCl}$ absorption with $\mathrm{K}^{+}$ requirement in the mouse kidney through $\mathrm{Na}-\mathrm{K}-2 \mathrm{Cl}$ (NKCC) co-transporter (Hebert and Andreoli, 1984; Sun et al., 1991), an action that seems to be mediated by recruitment of cotransporter to the apical membrane (Molony et al., 1987).

Several studies have demonstrated the importance of AVT in ion and water regulation in fish (Balment et al., 2006; Kulczykowska, 1997, 2001; Warne and Balment, 1995). Most of these studies focused on the effects of AVT in ion regulation and demonstrated it parallels AVP actions in mammals. For instance, in trunk kidney preparations of rainbow trout (Amer and Brown, 1995; Warne et al., 2002) and dogfish, Scyliorhinus canicula (Wells et al., 2002), AVT decreased urine output, an action probably linked to vascular effects. Additionally, a

\section{MATERIALS AND METHODS}

\section{Peptides and Chemicals}

Arginine vasotocin ([Arg8]-Vasotocin acetate), 5-Nitro-2-(3-phenylpropylamino) benzoic acid (NPPB) and Bumetanide (Bum) of the highest grade were purchased from SigmaAldrich (Madrid, Spain).

\section{Animals}

Sea bream (Sparus aurata) juveniles were obtained from commercial sources (Cupimar S.A., Cádiz, Spain). Fish were quarantined for 60 days in Ramalhete Marine Station (University of Algarve, Faro, Portugal) in $1000 \mathrm{~L}$ tanks with running seawater at a density $<5 \mathrm{~kg} / \mathrm{m}^{3}$ and 
handfed twice daily to a final ration of $2 \%$ body weight, with a commercial sea bream diet (Sorgal, Portugal). Fish were acclimated for at least 1 month before experimentation in flowing seawater (salinity 35 p.p.t.; water temperature $16-20^{\circ} \mathrm{C}$ ) under natural photoperiod for spring in the Algarve, Portugal. In all experiments, food was withheld for $36 \mathrm{~h}$ before sacrifice and tissue collection to ensure the absence of undigested food in the intestine.

For salinity adaptation juvenile sea bream $(n=90 ; 20-30 \mathrm{~g}$ body weight) were separated into three equal groups and transferred to $250 \mathrm{~L}$ tanks in 3 independent closed water circuits with biological filters maintained at final salinities of 12,35 or 55 p.p.t., temperature of $21^{\circ} \mathrm{C}$ and a 14:10 L:D photoperiod. Increase in salinity was achieved by adding Instant Ocean sea-salts to control seawater (35 p.p.t.), and decrease in salinity was achieved by dilution of full seawater with dechlorinated tap water. Fish were kept at different salinities for two months before tissue collection and were considered to be fully adapted (Laiz-Carrion et al., 2005). No mortality was registered during the trial and fish fed normally.

All animal manipulations were carried out in compliance with the Guidelines of the European Union Council (86/609/EU) and Portuguese and Spanish legislation for the use of laboratory animals. All animal protocols were performed under a "Group-I" licence from the DirecçãoGeral de Veterinária, Ministério da Agricultura, do Desenvolvimento Rural e das Pescas (Portugal).

\section{Cloning of AVT Receptor}

For cloning of the AVT Receptor degenerate primers were designed (Table I) against highly conserved cDNA sequences of piscine species: Platichthys flesus: (GenBank accession number AF184966); Astatotilapia burtoni: (acc. no. AF517936); Catostomus commersoni: (acc. no. X76321); Cyprinodon variegatus (Vla1; acc. no. GU120189); Cyprinodon variegatus (V1a2; acc. no. GU120190); Cyprynodon nevadensis amargosae (Vla1; acc. no. GU014233); Cyprynodon nevadensis amargosae (V1a2; acc. no. GQ981413). Tissues of unfed fish were collected into RNA Later (Sigma-Aldrich, Madrid, Spain) incubated for 24 hours at $4^{\circ} \mathrm{C}$ and stored at $-20^{\circ} \mathrm{C}$ until RNA extraction (within two weeks). Total RNA was isolated from brain, liver, kidney and gills using RNeasy® Plus MiniKit (Quiagen, Hidlen, Germany). Genomic DNA (gDNA) was eliminated with gDNA Eliminator spin columns (Quiagen, Hidlen, Germany). After reverse transcription of 500 ng total RNA (Super Script III, Invitrogen ${ }^{\mathrm{TM}} \mathrm{TM}$, Paisley, UK) PCR amplifications were carried out with Platinum ${ }^{\circledR}$ Taq DNA Polymerase (Invitrogen) using the following PCR conditions: $94^{\circ} \mathrm{C}, 1 \mathrm{~min}$ and 35 cycles 

of $94^{\circ} \mathrm{C}, 30 \mathrm{sec} ; 50^{\circ} \mathrm{C}, 30 \mathrm{sec} ; 72^{\circ} \mathrm{C}, 1 \mathrm{~min}$ and finalized with $72^{\circ} \mathrm{C}, 10 \mathrm{~min}$. PCR products were cloned into TA Vectors (TOPO TA Cloning ${ }^{\circledR}$ Kit; Invitrogen ${ }^{\mathrm{TM}}$, Paisley, UK), sequenced and identity confirmed by interrogating NCBI databases using the blastn protocol (Altschul et al., 1990).

To establish receptor identity/subtype amino acid sequences were retrieved from the NCBI protein database (www.ncbi.nlm.nih.gov, accessed in January 2013) and phylogenetic analysis of AVTR/AVPR translated sequences was performed using MEGA5 software (Tamura et al., 2011) with the Close-Neighbor-Interchange algorithm, based on amino acid differences (p-distances) and pairwise deletions. Reliability of the phylogenetic tree was assessed using bootstrap values (1,000 replicates).

\section{AVTR V1a2 in the sea bream intestine}

For AVTR V1a2-type expression analysis, specific primer pairs were designed using the software Primer3 (available in http://frodo.wi.mit.edu/) to amplify a $149 \mathrm{bp}$ of the AVTR V1a2-type (Table I). Total RNA was isolated using the E.Z.N.A. Total RNA Kit (OMEGA Bio-tek, Norcross, GA, USA) following the manufacturer's instructions, and the quantity and quality assessed (Nanodrop 1000, Thermo Scientific, Barrington, IL, USA). Total RNA was treated with DNase using an RNAse-free DNase kit (Ambion, Life Technologies, Paisley, UK). Total RNA (500 ng) was reverse transcribed (RevertAid ${ }^{\mathrm{TM}}$ First Strand cDNA Synthesis Kit, \#K1622, Fermentas, Thermo Scientific, Barrington, IL, USA)

Real-time qPCR amplifications were performed in duplicate in a final volume of 101 with 5 1 SsoFast EvaGreen Supermix (Bio- Rad, Hercules, CA, USA) as the reporter dye, $200 \mathrm{ng}$ cDNA, and $0.5 \mathrm{pM}$ of each forward and reverse primers. Amplifications were performed in 96-well plates using the One-step Plus sequence detection system (Applied Biosystems, Foster City, CA, USA) with the following protocol: denaturation and enzyme activation step at $95^{\circ} \mathrm{C}$ for $2 \mathrm{~min}$, followed by 40 cycles of $95^{\circ} \mathrm{C}$ for $5 \mathrm{sec}$ and $60^{\circ} \mathrm{C}$ for $10 \mathrm{sec}$. After the amplification phase, a temperature-determining dissociation step was carried out at $65^{\circ} \mathrm{C}$ for $15 \mathrm{~s}$, and $95^{\circ} \mathrm{C}$ for $15 \mathrm{~s}$. For normalization of cDNA loading, all samples were run in parallel using 18S ribosomal RNA (18S). To estimate efficiencies, a standard curve was generated for each primer pair from 10-fold serial dilutions (from 10 to $0.001 \mathrm{ng}$ ) of a pool of first-stranded cDNA template from all samples. Standard curves represented the cycle threshold value as a function of the logarithm of the number of copies generated, defined arbitrarily as one copy for the most diluted standard. All calibration curves exhibited correlation coefficients 
$158 \mathrm{R}^{2}>0.98$, and the corresponding real-time PCR efficiencies were $>99 \%$. Following this general method AVTR V1a2-type mRNA distribution in the gastrointestinal tract was analyzed in esophagus, stomach, pyloric caeca, anterior intestine, mid intestine and rectum of sea bream adapted to 35 p.p.t. In addition, the response of AVTR V1a2-type mRNA to external salinity was analyzed in the anterior intestine and in the rectum in sea bream adapted long-term to 12,35 and 55 p.p.t. external salinity.

\section{Short-circuit current (Isc) measurements}

The anterior intestine and rectum were collected, isolated and mounted in Ussing chambers as previously described (Gregorio et al., 2013). Briefly, tissue was placed on a tissue holder of $0.71 \mathrm{~cm}^{2}$ and positioned between two half- chambers containing $2 \mathrm{~mL}$ of physiological saline $\left(\mathrm{NaCl} 160 \mathrm{mM} ; \mathrm{MgSO}_{4} 1 \mathrm{mM} ; \mathrm{NaH}_{2} \mathrm{PO}_{4} 2 \mathrm{mM} ; \mathrm{CaCl}_{2}\right.$ 1.5mM; $\mathrm{NaHCO}_{3} 5 \mathrm{mM} ; \mathrm{KCl} 3 \mathrm{mM}$; Hydroxyethyl)piperazine- $\mathrm{N}^{\prime}-(2$-ethanesulfonic acid)) $4 \mathrm{mM}$ ), at a $\mathrm{pH}$ of 7.80 . During the experiments the tissue was bilaterally gassed with $0.3 \% \mathrm{CO}_{2}+99.7 \mathrm{O}_{2}$ and the temperature maintained at $22^{\circ} \mathrm{C}$. Short circuit current (Isc, $\mu \mathrm{A} / \mathrm{cm}^{2}$ ) was monitored by clamping of epithelia to $0 \mathrm{mV}$. Epithelial resistance (Rt, $\Omega . \mathrm{cm}^{2}$ ) was manually calculated (Ohm's law) using the current deflections induced by a $2 \mathrm{mV}$ pulse of $3 \mathrm{sec}$ every minute. Voltage clamping and current injections were performed by means of a DVC-1000 voltage clamp amplifier (WPI, Sarasota, USA) or a VCCMC2 (Physiologic Instruments, San Diego, USA). Bioelectrical parameters for each tissue were recorded after the tissue achieved a steady state, which occurred between 30-40 min after mounting.

The response to a single dose of $10^{-6} \mathrm{M}$ AVT was analyzed in preparations of anterior intestine and rectum collected from sea bream adapted long-term to 12, 35 and 55 p.p.t. external salinity. To test if AVT effects on intestinal Isc conform to typical dose-response effects, rectal tissue from fish adapted to 55 p.p.t. salinity were collected and mounted in Ussing chambers as described. After an initial period of Isc stabilization, tissues were treated at 45 min intervals with doses of $10^{-10}$ to $10^{-6} \mathrm{M}$ AVT at increased 10-fold intervals covering the range of circulating plasma values of AVT in the sea bream (Kleszczyska et al., 2006; Mancera et al., 2008).

Apical NPPB $(200 \mu \mathrm{M})$ or Bumetanide $(200 \mu \mathrm{M})$ were applied alone or in combination with $10^{-6} \mathrm{M}$ AVT in rectal tissue of fish adapted to 35 or 55 p.p.t. to identify the AVT-responsive 
mechanism. Concentration of specific blockers were selected to guarantee $100 \%$ inhibitory effects on a putative CFTR (NPPB) or a NKCC (Bumetanide)

\section{Statistics}

Results are presented as means \pm SEM unless otherwise stated. After normality and homogeneity of variance were checked, comparison between groups was analyzed as appropriate using the Student's t-test or One-way analysis of variance (ANOVA) followed by the post-hoc Bonferroni test. All statistical analysis was performed with Prism 5.0 (GraphPad Software for Macintosh) and groups were considered significantly different at $p<0.05$.

\section{RESULTS}

\section{cDNA for AVT Receptor}

A cDNA for a partial AVT receptor spanning $392 \mathrm{bp}$ of the coding sequence was isolated and clusters with the AVTR V1a2-type as shown by phylogenetic analysis (Figure 1).

AVTR V1a2 is expressed throughout the intestinal tract: esophagus, stomach, pyloric caeca, anterior intestine, mid intestine and rectum (Figure 2A). Furthermore expression increased in more distal portions of the intestinal tract, with highest expression in the rectum when compared to all other regions (Figure 2B).

After acclimation of sea bream to external salinities of 12,35 and 55 p.p.t., AVTR V1a2 transcript abundance in the anterior intestine paralleled decreases/increases of external salinity with significantly lower expression levels at 12 p.p.pt. (Figure 3). In addition, the transcript abundance of AVTR V1a2 was significantly higher in the rectum compared to the anterior intestine at all salinities.

\section{AVT intestinal electrophysiology}

Basal values of short circuit current (Isc, $\mathrm{mA} / \mathrm{cm}^{2}$ ) and tissue resistance (Rt, $\Omega . \mathrm{cm}^{2}$ ) are shown in Table II. Positive Isc recorded show secretory currents while absorptive currents are shown by negative values. Control preparations sustained constant Isc and Rt for the duration of the experimental periods (up to 3.5 hours). In general the effects of salinity followed the pattern previously described for the sea bream intestine (Gregorio et al., 2013). In the anterior intestine a small absorptive current was observed in fish at 35 and 55 p.p.t., while at 12 p.p.t. a secretory current was recorded (Table 2). In contrast the rectum of fish acclimated to 35 and 
55 p.p.t. showed a secretory current, which in low salinity adapted fish was highly variable but averaged a small absorptive current.

The basolateral application of $10^{-6} \mathrm{M}$ AVT to preparations of anterior intestine and rectum from fish at 55, 35 and 12 p.p.t did not affect tissue resistance (Rt, data not shown). In contrast, AVT evoked a rapid stimulatory action on Isc, (Figure 4) in the absorptive direction in all intestinal regions (the current became either more negative or less positive). The effects of AVT on Isc were rapid, with an onset between 3-5 min of application and reached maximal effects within 25-30 min after application (Figure 4A). Interestingly, the effect of AVT in the anterior intestine was higher in fish adapted to 12 p.p.t., while in the rectum it was higher in fish adapted to 55 p.p.t.

To test whether AVT effects on Isc conform to a typical dose-response curve AVT $\left(10^{-10}\right.$ $10^{-6} \mathrm{M}$ ) was sequentially applied to rectal tissue of fish adapted to 55 p.p.t. (as the highest responder to AVT). The dose-response effects of AVT on Isc were linear, with no apparent plateau, and a threshold with significant effects occurred at concentrations of $10^{-8} \mathrm{M}$ AVT with Isc decreases of $-6.2 \mu \mathrm{A} / \mathrm{cm}^{2}$ and a maximal effect of $-13.2 \mu \mathrm{A} / \mathrm{cm}^{2}$ was achieved with $10^{-6} \mathrm{M}$ AVT.

Higher responses to AVT were obtained in tissues with a positive short circuit current presumably secretory (Table 2). To test the dependence of these currents on a putative CFTR, a selective inhibitor NPPB $(200 \mu \mathrm{M})$ was applied apically to preparations of rectum collected from fish adapted to 35 and 55 p.p.t. NPPB produced a significant fall in the Isc recorded i.e. $-4 \mu \mathrm{A} / \mathrm{cm}^{2}$ in the rectum of 35 p.p.t. acclimated fish and $-14 \mu \mathrm{A} / \mathrm{cm}^{2}$ in the rectum of 55 p.p.t. acclimated fish (Figure 6).

To test whether the effects of AVT on Isc were mediated by regulation of the secretory or absorptive pathways, rectal tissues of fish acclimated to 35 and 55 p.p.t. were tested in Ussing chamber in the presence or absence of apical NPPB $(200 \mu \mathrm{M})$ or bumetanide $(200 \mu \mathrm{M})$. NPPB did not modify the response to $10^{-6} \mathrm{M}$ AVT of rectal tissue from fish acclimated to 55 or 35 p.p.t seawater (Figure 7). In contrast, apical bumetanide (200 $\mu \mathrm{M})$ completely abolished

\section{DISCUSSION}

254 In keeping with the proposed role for AVT in ion and water balance in teleosts (Balment et 255 al., 2006; Kulczykowska, 1997, 2001; Warne and Balment, 1995), the present study 
established the intestine of marine teleosts as a target for a physiological role for the vasotocinergic system. We show the heterogeneous distribution and salinity dependence of the expression of a V1a2-type AVT receptor in the gastrointestinal tract and characterized the involvement of AVT on ion movements in Ussing chambers. The effect of AVT on ion transport in the intestine seems to be mediated by a bumetanide sensitive mechanism, likely a NKCC co-transporter.

The sea bream cope with large changes in environmental salinity ranging from 5 to 60 p.p.t. (Laiz-Carrión et al., 2005), but are unable to withstand freshwater (Fuentes et al., 2010a). Acclimation to salinity occurs through water absorption and ion balance mechanisms in the gills and intestine (Fuentes et al., 2006; Fuentes et al., 2010b; Gregorio et al., 2013; Raldúa et al., 2008). Furthermore, the gastrointestinal tract of the sea bream is a target for endocrine regulation of ion transport (Ferlazzo et al., 2012; Fuentes et al., 2010a; Fuentes et al., 2006; distribution of receptors for AVP/AVT in the intestine of birds (Tan et al., 2000), amphibians (Hasunuma et al., 2010) and mammals (Lolait et al., 1992; Morel et al., 1993). In fish, the intestinal expression of AVT receptor V1a-type and V2-type have been demonstrated in the African lungfish, Protopterus annectens (Konno et al., 2009). In addition, in the Amargosa River pupfish (Cyprinodon nevadensis amargosae) three different types of AVT receptors i.e. V1a1-type, V1a2-type and V2-type, are described (Lema, 2010). Our analysis of the sea bream partial AVT receptor indicates that it corresponds to an AVTR V1a2-type, one of the subtypes of the AVTR V1a described in teleosts (Figure 1), although the subtype V1a of the AVTR/AVPR has been associated with vascular smooth muscle (V1a1/V1) or preferentially described in the pituitary corticotrophe cells (V1a2/V1b) (Mahlmann et al., 1994; Verbalis, 2002). The expression of the AVTR V1a2-type receptor throughout the gastrointestinal tract of the sea bream highlights a potential role for the vasotocinergic system in the intestine. Furthermore, expression of AVT V1a2 is high in the esophagus, and there is an apparent antero-posterior increase from pyloric caeca to rectum, where it is expressed at the highest level (Figure 2). Additionally, salinity seems to act as regulatory trigger for AVT receptor expression in the Amargosa River pupfish (Lema, 2010), although, the only receptor that seems to sustain higher branchial expression in response to salinity is the V1a2-subtype, at least at $20 \mathrm{~h}$ post challenge (Lema, 2010). In the sea bream, we show that a long-term challenge with varying external salinity impacts the expression of V1a2-type AVT receptor in the intestine (Figure 3). It is tempting to suggest that the regionalization and transcriptional 
response to salinity of the V1a2-type AVT receptor are both related to functional specificity in ion regulation of discrete regions of the intestine in sea bream as has previously been described (Gregorio et al., 2013).

292 The intestine of fish maintains both absorptive and secretory pathways. $\mathrm{Cl}^{-}$uptake via NKCC co-transporters (Musch et al., 1982) or apical anion $\mathrm{Cl}^{-} / \mathrm{HCO}_{3}{ }^{-}$exchangers (Grosell, 2011; Grosell et al., 2005) act to produce the driving force for water absorption. Additionally, the intestinal epithelium of Fundulus heteroclitus mounted in Ussing chambers can switch from net $\mathrm{Cl}^{-}$absorption to net $\mathrm{Cl}^{-}$secretion as shown by directional changes of the tissue short circuit current (Marshall et al., 2002). The sea bream intestine has preferential $\mathrm{Cl}^{-}$absorption or secretion depending on external salinity and intestinal region (Carvalho et al., 2012; Gregorio et al., 2013). In the present study we describe how changes in external salinity and target tissue condition the response to a single dose of AVT in the anterior intestine and the rectum of the sea bream (Figure 4A). A consistent feature of the responses to AVT by the sea bream intestine in vitro is the consistency of the effect, always in the absorptive direction. AVT makes Isc less positive (or more negative) in all cases either by decreasing secretion or by increasing absorptive currents. However, the magnitude of absorption stimulation is different in different regions of the sea bream intestine. Interestingly, preparations from tissues with positive currents i.e. secretory ( $\operatorname{Isc}>0$ ) have the highest response to AVT and this is the case of the anterior intestine from fish maintained at low salinity (12 p.p.t.) and the rectum of fish kept in hyperosmotic conditions i.e. 35 and 55 p.p.t. (Figure 4B). In the latter we show that apical application of NPPB, a potent chloride channel blocker specific to CFTR (McCarty, 2000), results in decreases of the basal current of $-3.5 \mu \mathrm{A} / \mathrm{cm}^{2}$ in fish at 35 p.p.t. and $-14 \mu \mathrm{A} / \mathrm{cm}^{2}$, in fish at 55 p.p.t. demonstrating the presence of a functional CFTR.

AVT has a stimulatory action on $\mathrm{Cl}^{-}$secretion in cultured pavement cells of the sea bass gill via a DPC-sensitive mechanism, likely CFTR (Avella et al., 1999; Guibbolini and Avella, 2003). Surprisingly, the effect of AVT on Isc in the intestine of the sea bream paralleled in direction and magnitude the inhibitory effect of NPPB on basal currents specifically in the rectum, that could be the reflection of a pharmacological effect of the high concentration of AVT $\left(10^{-6} \mathrm{M}\right)$ in the Ussing chamber. However, the effects of AVT followed a linear doseresponse in the range of $10^{-10}-10^{-6} \mathrm{M}$ and the effect of AVT has no apparent plateau up to the highest concentration of AVT used $\left(10^{-6} \mathrm{M}\right)$. This is in keeping with the previous report of heterologous expression of P. flesus AVT receptor in Xenopus oocytes where the response to AVT did not reach a plateau at concentrations in a range of $10^{-14}$ to $10^{-10} \mathrm{M}$ (Warne, 2001). 
322 Furthermore, regardless of the concentration, AVT actions are not mediated by regulation of the secretory pathway via CFTR. On the contrary a consistent single stimulatory effect on the absorptive pathway was observed. This is also supported by the unchanged stimulatory effect of AVT on the absorptive current recorded in the presence or absence of apical NPPB (Figure 7). Remarkably, the hormone level at which a significant response to AVT occurred was $10^{-8}$ $\mathrm{M}$, which falls within circulating plasma levels (2-30 $\mathrm{nM})$ of AVT in the sea bream (Kleszczyska et al., 2006; Mancera et al., 2008). The present results in the sea bream contrast with previous reports in tilapia where AVT $(2 \mu \mathrm{g} / \mathrm{mL})$ was without effect on water, sodium and chloride transport in the anterior intestine either in freshwater- or seawater-adapted fish (Mainoya, 1985). However, our results support an important physiological role for AVT in the regulation of ion transport in the marine fish intestine in vivo. This role for AVT is likely more important during hyperosmotic adaptation and is probably linked with the functional specialization of the sea bream intestine, specially at high salinities (Gregorio et al., 2013). Interestingly, high salinity challenge results in coordinated increases/decreases of plasma AVT/pituitary storage, respectively (Balment et al., 2006; Kulczykowska, 1997, 2001; Warne and Balment, 1995). Therefore, the linear response of the sea bream intestine to increasing doses of AVT indicates that the receptor is not a limiting factor of the biological action in ion transport. In rats AVP regulates the expression of secretory-type Na-K-2Cl co-transporter (NKCC1) mRNA and protein in a dose-dependent manner in the outer medullary-collecting duct (OMCD), and therefore promotes the secretory pathway (Wakamatsu et al., 2009). However, AVP also controls NKCC2, the absorptive form of the Na-K-2Cl co-transporter (Ares et al., 2011). It seems that the action of AVT in the intestine of the sea bream is achieved solely by its stimulatory effect on the absorptive pathway, which is preferentially mediated by the Na$\mathrm{K}-2 \mathrm{Cl}$ co-transporter (Musch et al., 1982). The loop diuretic bumetanide is a specific inhibitor of the NKCC (Haas, 1994) and when applied apically to sea bream rectum preparations, abolished almost completely the stimulatory effect of AVT in the absorptive Isc (Figure 7), and indicates there is functional association, likely similar to that described in the thick ascending limb of the loop of Henle in terrestrial vertebrates (Ares et al., 2011). However, it remains to be established if these effects are achieved solely via the AVT V1a2-receptor type. In conclusion, the present study provides strong evidence that AVT is involved in the regulation of ion transport in the intestine of the sea bream. At least one AVT receptor, which 
is distributed throughout the gastrointestinal tract, is expressed in response to salinity challenge in different intestinal regions. The intestinal of the sea bream in vitro responds to stimulation with AVT, an effect that is region and salinity dependent. Threshold Lowest effective doses for significant effects of AVT at concentrations similar to circulating plasma levels of the hormone support the physiological relevance of this regulation, which is likely achieved via apical NKCC2.

\section{ACKNOWLEDGMENTS}

JAM-S is funded by Ministry of Education (Spain) through the program "Formación de Profesorado Universitario" (Ref: AP2008-01194). This work was partially supported by Ministry of Science and Education, Spain by Project AGL2010-14876 to JMM and by the Ministry of Science and Higher Education and European Social Funds through the Portuguese National Science Foundation by Project PTDC/MAR/104008/2008 to JF.

\section{REFERENCES}

Acher, R., 1993. Neurohypophysial peptide systems: processing machinery, hydro-osmotic regulation, adaptation and evolution. Regulatory Peptides 45, 1-13.

Altschul, S.F., Gish, W., Miller, W., Myers, E.W., Lipman, D.J., 1990. Basic local alignment search tool. J Mol Biol 215, 403-410.

Amer, S., Brown, J.A., 1995. Glomerular actions of arginine vasotocin in the in situ perfused trout kidney. Am J Physiol 269, R775-780.

Ares, G.R., Caceres, P.S., Ortiz, P.A., 2011. Molecular regulation of NKCC2 in the thick ascending limb. Am J Physiol Renal Physiol 301, F1143-1159.

Avella, M., Part, P., Ehrenfeld, J., 1999. Regulation of Cl- secretion in seawater fish (Dicentrarchus labrax) gill respiratory cells in primary culture. Journal of Physiology 516, 353-363.

Balment, R.J., Lu, W., Weybourne, E., Warne, J.M., 2006. Arginine vasotocin a key hormone in fish physiology and behaviour: A review with insights from mammalian models. Gen Comp Endocr 147, 9-16.

Bernard, K., Bogliolo, S., Ehrenfeld, J., 2005. Vasotocin and vasopressin stimulation of the chloride secretion in the human bronchial epithelial cell line, 16HBE14o. British Journal of Pharmacology 144, 1037-1050.

Carvalho, E.S., Gregorio, S.F., Power, D.M., Canario, A.V., Fuentes, J., 2012. Water absorption and bicarbonate secretion in the intestine of the sea bream are regulated by transmembrane and soluble adenylyl cyclase stimulation. J Comp Physiol B 182, 1069-1080. Conklin, D.J., Smith, M.P., Olson, K.R., 1999. Pharmacological characterization of arginine vasotocin vascular smooth muscle receptors in the trout (Oncorhynchus mykiss) in vitro. Gen Comp Endocr 114, 36-46. of gas exchange, osmoregulation, acid-base regulation, and excretion of nitrogenous waste. Physioloical Reviews 85, 97-177. 
Ferlazzo, A., Carvalho, E.S., Gregorio, S.F., Power, D.M., Canario, A.V., Trischitta, F., Fuentes, J., 2012. Prolactin regulates luminal bicarbonate secretion in the intestine of the sea bream (Sparus aurata L.). J Exp Biol 215, 3836-3844.

Fuentes, J., Brinca, L., Guerreiro, P.M., Power, D.M., 2010a. PRL and GH synthesis and release from the sea bream (Sparus auratus L.) pituitary gland in vitro in response to osmotic challenge. Gen Comp Endocrinol 168, 95-102.

Fuentes, J., Figueiredo, J., Power, D.M., Canário, A.V.M., 2006. Parathyroid hormone-related protein regulates intestinal calcium transport in sea bream (Sparus auratus). American Journal of Physiology - Regulatory Integrative and Comparative Physiology 291, R1499-R1506.

Fuentes, J., Power, D.M., Canário, A.V.M., 2010b. Parathyroid hormone-related proteinstanniocalcin antagonism in regulation of bicarbonate secretion and calcium precipitation in a marine fish intestine. American Journal of Physiology - Regulatory Integrative and Comparative Physiology 299, R150-R158.

Fuentes, J., Soengas, J.L., Rey, P., Rebolledo, E., 1997. Progressive transfer to seawater enhances intestinal and branchial $\mathrm{Na}+-\mathrm{K}+$-ATPase activity in nonanadromous rainbow trout. Aquaculture International 5, 217-227.

Goodson, J.L., 2008. Nonapeptides and the evolutionary patterning of sociality. Prog Brain Res 170, 3-15.

Gregorio, S.F., Carvalho, E.S., Encarnacao, S., Wilson, J.M., Power, D.M., Canario, A.V., Fuentes, J., 2013. Adaptation to different salinities exposes functional specialization in the intestine of the sea bream (Sparus aurata L.). Journal of Experimental Biology 216, 470-479.

Grosell, M., 2006. Intestinal anion exchange in marine fish osmoregulation. J Exp Biol 209, 2813-2827.

Grosell, M., 2011. Intestinal anion exchange in marine teleosts is involved in osmoregulation and contributes to the oceanic inorganic carbon cycle. Acta Physiol. (Oxf.) 202, 421-434.

Grosell, M., Wood, C.M., Wilson, R.W., Bury, N.R., Hogstrand, C., Rankin, C., Jensen, F.B., 2005. Bicarbonate secretion plays a role in chloride and water absorption of the European flounder intestine. Am J Physiol Regul Integr Comp Physiol 288, R936-946.

Guibbolini, M.E., Avella, M., 2003. Neurohypophysial hormone regulation of Cl- secretion: Physiological evidence for V1-type receptors in sea bass gill respiratory cells in culture. Journal of Endocrinology 176, 111-119.

Haas, M., 1994. The Na-K-Cl cotransporters. Am J Physiol 267, C869-885.

Hasunuma, I., Toyoda, F., Kadono, Y., Yamamoto, K., Namiki, H., Kikuyama, S., 2010. Localization of three types of arginine vasotocin receptors in the brain and pituitary of the newt Cynops pyrrhogaster. Cell Tissue Res 342, 437-457.

Hebert, S.C., Andreoli, T.E., 1984. Control of $\mathrm{NaCl}$ transport in the thick ascending limb. Am J Physiol 246, F745-756.

Kalujnaia, S., McWilliam, I.S., Zaguinaiko, V.A., Feilen, A.L., Nicholson, J., Hazon, N., Cutler, C.P., Cramb, G., 2007. Transcriptomic approach to the study of osmoregulation in the European eel Anguilla anguilla. Physiol Genomics 31, 385-401.

Kleszczyska, A., Vargas-Chacoff, L., Gozdowska, M., Kalamarz, H., Martínez-Rodríguez, G., Mancera, J.M., Kulczykowska, E., 2006. Arginine vasotocin, isotocin and melatonin responses following acclimation of gilthead sea bream (Sparus aurata) to different environmental salinities. Comparative Biochemistry and Physiology - A Molecular and Integrative Physiology 145, 268-273.

Konno, N., Hyodo, S., Yamaguchi, Y., Kaiya, H., Miyazato, M., Matsuda, K., Uchiyama, M., 2009. African lungfish, Protopterus annectens, possess an arginine vasotocin receptor homologous to the tetrapod V2-type receptor. Journal of Experimental Biology 212, 21832193. 
Kozaka, T., Fujii, Y., Ando, M., 2003. Central effects of various ligands on drinking behavior in eels acclimated to seawater. Journal of Experimental Biology 206, 687-692.

Kulczykowska, E., 1997. Response of circulating arginine vasotocin and isotocin to rapid osmotic challenge in rainbow trout. Comparative Biochemistry and Physiology - A Physiology 118, 773-778.

Kulczykowska, E., 2001. Responses of circulating arginine vasotocin, isotocin, and melatonin to osmotic and disturbance stress in rainbow trout (Oncorhynchus mykiss). Fish Physiology and Biochemistry 24, 201-206.

Kulczykowska, E., 2007. Arginine Vasotocin and Isotocin: Towards Their Role in Fish Osmoregulation. In : Fish Osmoregulation B. Baldisserotto, J. M. Mancera Romero and B.G. Kapoor (Eds.). Science Publisher, Enfield (NH), 151-176.

Laiz-Carrión, R., Guerreiro, P.M., Fuentes, J., Canário, A.V.M., Martín Del Río, M.P., Mancera, J.M., 2005. Branchial osmoregulatory response to salinity in the gilthead sea bream, Sparus auratus. Journal of Experimental Zoology Part A: Comparative Experimental Biology 303, 563-576.

Laiz-Carrion, R., Sangiao-Alvarellos, S., Guzman, J.M., del Rio, M.P.M., Soengas, J.L., Mancera, J.M., 2005. Growth performance of gilthead sea bream Sparus aurata in different osmotic conditions: Implications for osmoregulation and energy metabolism. Aquaculture 250, 849-861.

Lema, S.C., 2010. Identification of multiple vasotocin receptor cDNAs in teleost fish: Sequences, phylogenetic analysis, sites of expression, and regulation in the hypothalamus and gill in response to hyperosmotic challenge. Mol Cell Endocrinol 321, 215-230.

Lolait, S.J., O'Carroll, A.M., McBride, O.W., Konig, M., Morel, A., Brownstein, M.J., 1992. Cloning and characterization of a vasopressin V2 receptor and possible link to nephrogenic diabetes insipidus. Nature 357, 336-339.

Mahlmann, S., Meyerhof, W., Hausmann, H., Heierhorst, J., Schönrock, C., Zwiers, H., Lederis, K., Richter, D., 1994. Structure, function, and phylogeny of [Arg8]vasotocin receptors from teleost fish and toad. Proceedings of the National Academy of Sciences of the United States of America 91, 1342-1345.

Mainoya, J.R., 1985. Effect of peptide hormones on intestinal transport in fish. In Current Trends in Comparative Endocrinology vol 2. Lofts, B. and Holmes, W. N. editors. Hong Kong University Press, Hong Kong, ISBN 962-209-116-4 (Volume II) pp 910-913.

Mancera, J.M., Vargas-Chacoff, L., Garcia-Lopez, A., Kleszczynska, A., Kalamarz, H., Martinez-Rodriguez, G., Kulczykowska, E., 2008. High density and food deprivation affect arginine vasotocin, isotocin and melatonin in gilthead sea bream (Sparus auratus). Comp Biochem Physiol A Mol Integr Physiol 149, 92-97.

Marshall, W.S., Howard, J.A., Cozzi, R.R.F., Lynch, E.M., 2002. NaCl and fluid secretion by the intestine of the teleost Fundulus heteroclitus: involvement of CFTR. Journal of Experimental Biology 205, 745-758.

McCarty, N.A., 2000. Permeation through the CFTR chloride channel. J Exp Biol 203, 19471962.

Molony, D.A., Reeves, W.B., Hebert, S.C., Andreoli, T.E., 1987. ADH increases apical Na+, $\mathrm{K}+, 2 \mathrm{Cl}$ - entry in mouse medullary thick ascending limbs of Henle. Am J Physiol 252, F177187.

Mordasini, D., Bustamante, M., Rousselot, M., Martin, P.Y., Hasler, U., Féraille, E., 2005. Stimulation of $\mathrm{Na}+$ transport by AVP is independent of PKA phosphorylation of the Na-KATPase in collecting duct principal cells. American Journal of Physiology - Renal Physiology 289, F1031-F1039.

Morel, A., Lolait, S.J., Brownstein, M.J., 1993. Molecular cloning and expression of rat V1a and V2 arginine vasopressin receptors. Regul Pept 45, 53-59. 
Musch, M.W., Orellana, S.A., Kimberg, L.S., Field, M., Halm, D.R., Krasny, E.J., Jr., Frizzell, R.A., 1982. Na+-K+-Cl- co-transport in the intestine of a marine teleost. Nature 300, 351-353.

Raldúa, D., Otero, D., Fabra, M., Cerdá , J., 2008. Differential localization and regulation of two aquaporin-1 homologs in the intestinal epithelia of the marine teleost Sparus aurata. American Journal of Physiology - Regulatory Integrative and Comparative Physiology 294, R993-R1003.

Schafer, J.A., Troutman, S.L., Schlatter, E., 1990. Vasopressin and mineralocorticoid increase apical membrane driving force for $\mathrm{K}+$ secretion in rat $\mathrm{CCD}$. American Journal of Physiology - Renal Fluid and Electrolyte Physiology 258, F199-F210.

Sun, A., Grossman, E.B., Lombardi, M., Hebert, S.C., 1991. Vasopressin alters the mechanism of apical Cl- entry from $\mathrm{Na}+: \mathrm{Cl}-$ to $\mathrm{Na}+: \mathrm{K}+: 2 \mathrm{Cl}$ - cotransport in mouse medullary thick ascending limb. J Membr Biol 120, 83-94.

Tamura, K., Peterson, D., Peterson, N., Stecher, G., Nei, M., Kumar, S., 2011. MEGA5: molecular evolutionary genetics analysis using maximum likelihood, evolutionary distance, and maximum parsimony methods. Mol Biol Evol 28, 2731-2739.

Tan, F.L., Lolait, S.J., Brownstein, M.J., Saito, N., MacLeod, V., Baeyens, D.A., Mayeux, P.R., Jones, S.M., Cornett, L.E., 2000. Molecular cloning and functional characterization of a vasotocin receptor subtype that is expressed in the shell gland and brain of the domestic chicken. Biol Reprod 62, 8-15.

Verbalis, J.G., 2002. Vasopressin V2 receptor antagonists. J Mol Endocrinol 29, 1-9.

Wakamatsu, S., Nonoguchi, H., Ikebe, M., Machida, K., Izumi, Y., Memetimin, H., Nakayama, Y., Nakanishi, T., Kohda, Y., Tomita, K., 2009. Vasopressin and hyperosmolality regulate NKCC1 expression in rat OMCD. Hypertens Res 32, 481-487.

Warne, J.M., 2001. Cloning and characterization of an arginine vasotocin receptor from the euryhaline flounder Platichthys flesus. Gen Comp Endocr 122, 312-319.

Warne, J.M., Balment, R.J., 1995. Effect of acute manipulation of blood volume and osmolality on plasma [AVT] in seawater flounder. American Journal of Physiology Regulatory Integrative and Comparative Physiology 269, R1107-R1112.

Warne, J.M., Harding, K.E., Balment, R.J., 2002. Neurohypophysial hormones and renal function in fish and mammals. Comparative Biochemistry and Physiology - B Biochemistry and Molecular Biology 132, 231-237.

Wells, A., Anderson, W.G., Hazon, N., 2002. Development of an in situ perfused kidney preparation for elasmobranch fish: Action of arginine vasotocin. American Journal of Physiology - Regulatory Integrative and Comparative Physiology 282, R1636-R1642. 
533 Table I. Primers used for molecular identification of partial cDNA sequences of the AVT-R 534 and for qPCR expression analysis.

535

\begin{tabular}{|c|c|}
\hline Degenerate primers & Nucleotide sequence \\
\hline$A V T-R F w$ & 5'- AGCGTSCTGCTGGCSATG -3' \\
\hline$A V T-R R v$ & 5'-GCAKATRAASCCGTAGCA -3' \\
\hline AVT-Rnested-Fw & 5'- AARCACCTSAGCCTBGCBGA -3' \\
\hline AVT-Rnested-Rv & 5'- GTBATCCAGGTGATGTASGC -3' \\
\hline \multicolumn{2}{|l|}{ qPCR primers } \\
\hline$A V T R F w$ & 5'- TTATCTCAACGTGGATGTGCAG-3' \\
\hline$A V T R R v$ & 5'- TTACCAGGTGATGTAGGCCTTG -3' \\
\hline $18 s F w$ & 5'- AACCAGACAAATCGCTCCAC-3' \\
\hline $18 s R v$ & 5'- CCTGCGGCTTAATTTGACTC-3' \\
\hline
\end{tabular}


537 Table II. Bioelectrical properties of discrete regions of the intestine of the sea bream mounted 538 in Ussing chambers and short-circuited to $\mathrm{Vt}=0 \mathrm{mV}$. Fish underwent long-term acclimation 539 to water salinities of 12,35 and 55 p.p.t. The number of fish utilized for each portion of 540 intestine and each salinity is indicated in brackets. Isc $\left(\mu \mathrm{Amp} / \mathrm{cm}^{2}\right)$ and $\mathrm{Rt}\left(\Omega . \mathrm{cm}^{2}\right)$ within the 541 same intestinal region displaying different letters were significantly different $(\mathrm{p}<0.05$, One542 way ANOVA followed by Bonferroni post-hoc test). Asterisks represent significant 543 differences between intestinal regions at the same salinity ( $p<0.05$, Student t-test).

544

\begin{tabular}{cccc}
\cline { 3 - 3 } & & $\begin{array}{c}\text { Isc } \\
\left(\boldsymbol{\mu A m p} / \mathbf{c m}^{\mathbf{2}}\right)\end{array}$ & $\begin{array}{c}\mathbf{R t} \\
\left(\boldsymbol{\Omega} . \mathbf{c m}^{\mathbf{2}}\right)\end{array}$ \\
\hline \multirow{2}{*}{ Anterior intestine } & $\mathbf{3 5}$ p.p.t. $(\mathbf{n}=\mathbf{1 2})$ & $-6.99 \pm 1.77^{\mathrm{b}}$ & $75.57 \pm 10.71^{\mathrm{a}}$ \\
& $\mathbf{5 5}$ p.p.t. $(\mathbf{n}=\mathbf{1 3})$ & $-4.06 \pm 2.11^{\mathrm{b}}$ & $113.24 \pm 12.75^{\mathrm{b}}$ \\
\hline \multirow{2}{*}{ Rectum } & $\mathbf{1 2}$ p.p.t. $(\mathbf{n}=\mathbf{1 1})$ & $-1.37 \pm 1.78^{\mathrm{a} *}$ & $65.05 \pm 4.08^{\mathrm{a} *}$ \\
& 35 p.p.t. $(\mathbf{n}=\mathbf{1 2})$ & $3.93 \pm 1.06^{\mathrm{b} *}$ & $64.81 \pm 4.55^{\mathrm{a} *}$ \\
& $\mathbf{5 5}$ p.p.t. $(\mathbf{n}=\mathbf{1 1})$ & $16.35 \pm 2.26^{\mathrm{c} *}$ & $90.93 \pm 9.98^{\mathrm{b} *}$ \\
\hline
\end{tabular}


Figure 1. AVP/AVT receptor phylotree inferred using the Maximum Parsimony (MP) method and 1000 bootstrap replicates. The MP tree was obtained using the Close-NeighborInterchange algorithm in MEGA5 using alignments generated by CLUSTALW. GenBank and Ensembl accession numbers of amino acid sequences are as follows: Oryzias latipes V1a1 (BAL45623), V1a2 (BAL45624) and V2 (BAJ04637); Thalassoma bifasciatum V1a1 AFJ96998) and V1a2 (BAL70406); Epineohelus adscensionis V1a1 (AEI54996) and V1a2 (ADO33897); Cyprinodon nevadensis amargosae V1a1 (ACY07771), V1a2 (ACY07772) and V2 (ACX85730); Cyprinodon variegatus V1a1 (ACY74366), V1a2 (ACY74367) and V2 (ACY74368); Homo sapiens V1a (AAD17891) and V2 (ACR39021); Amphiprion ocellaris V2 (BAL70406); Protopterus annectens V2 (AB377532); and Polypterus senegalus V2 (BAJ04635)

Figure 2. Distribution of AVT V1a2-type receptor in discrete sections of the gastrointestinal tract of the sea bream adapted to seawater (35 p.p.t.). A, Ethidium bromide stained gels. B, Relative expression of AVTR as measured by qPCR. Results are presented as average + SEM $(n=4)$. Columns displaying different letters are significantly different $(p<0.05$, One-way ANOVA followed by Bonferroni post-hoc test). Key to the figure: Eso: oesophagus; Sto: stomach; PC: pyloric caeca; Ant. intest.: anterior intestine; Mid intest.: mid intestine; -C: negative control.

Figure 3. Relative expression of AVT V1a2-type receptor in the anterior intestine and the rectum of the sea bream after long-term acclimation to 12, 35 and 55 p.p.t seawater. Results are shown in arbitrary units (AVTR/18S) determined by qPCR. Each column represents the average $\pm \operatorname{SEM}(n=7)$. Within intestinal region columns displaying different letters are significantly different $(\mathrm{p}<0.05$, One-way ANOVA followed by Bonferroni post-hoc test). Asterisks represent significant differences between intestinal regions at the same salinity $(p<0.05$, Student t-test).

Figure 4. A. Original trace of short-circuit current (Isc, $\mu \mathrm{A} / \mathrm{cm}^{2}$ ) recorded after basolateral application of AVT $10^{-6} \mathrm{M}$ to the rectum from sea bream acclimated to 55 p.p.t. Vertical current deflections are generated by $\pm 1 \mathrm{mV}$ pulses to calculate Rt. B. Changes in the effects of basolateral AVT $10^{-6} \mathrm{M}$ in the short circuit $\left(\Delta \mathrm{Isc}, \mu \mathrm{Amp} / \mathrm{cm}^{2}\right)$ in anterior intestine and 
580 rectum of the sea bream. Fish underwent long-term acclimation to changing external salinity 58112,35 and 55 p.p.t. Each column represents the average + SEM $(n=6-8)$. Within intestinal 582 region columns displaying different letters are significantly different $(p<0.05$, One-way 583 ANOVA followed by Bonferroni post-hoc test).

585 Figure 5. Changes in short-circuit current $\left(\Delta \mathrm{Isc}, \mu \mathrm{Amp} / \mathrm{cm}^{2}\right)$ measured in Ussing chambers in 586 response to consecutive basolateral addition of AVT $\left(10^{-10}-10^{-6} \mathrm{M}\right)$ to rectum from sea bream 587 acclimated to 55 p.p.t. Each point represents the average \pm SEM ( $n=3)$. Asterisks represent 588 significant differences from controls $(p<0.05$, One-way ANOVA followed by Bonferroni 589 post-hoc test).

591 Figure 6. NPPB-sensitive short-circuit current (Isc, $\mu \mathrm{Amp} / \mathrm{cm}^{2}$ ) in the rectum of sea bream 592 adapted to 35 or 55 p.p.t. Basal values of Isc are shown for epithelia after a stabilization 593 period followed by apical addition of NPPB $(200 \mu \mathrm{M})$. Results are shown as mean \pm SEM $594(\mathrm{n}=5-6)$. Asterisks represent significant differences from basal values $(p<0.05$, Student's t595 test).

597 Figure 7. AVT-dependent short circuit current $\left(\Delta \mathrm{Isc}, \mu \mathrm{Amp} / \mathrm{cm}^{2}\right)$ in the rectum of juvenile 598 sea bream acclimated to 35 or 55 p.p.t. meassured in Using chambers. AVT was tested alone 599 (AVT; $\left.10^{-6} \mathrm{M}\right)$ or in combination with apical NPPB $(+\mathrm{NPPB}, 200 \mu \mathrm{M})$ or bumetanide (+Bum, $600200 \mu \mathrm{M})$. ND, Not determined. Results are shown as mean+SEM (n=6). Asterisks represent 601 significant differences from AVT alone ( $p<0.05$, One-way ANOVA followed by Bonferroni 602 post-hoc test). 
Figure 1. Martos-Sitcha et al

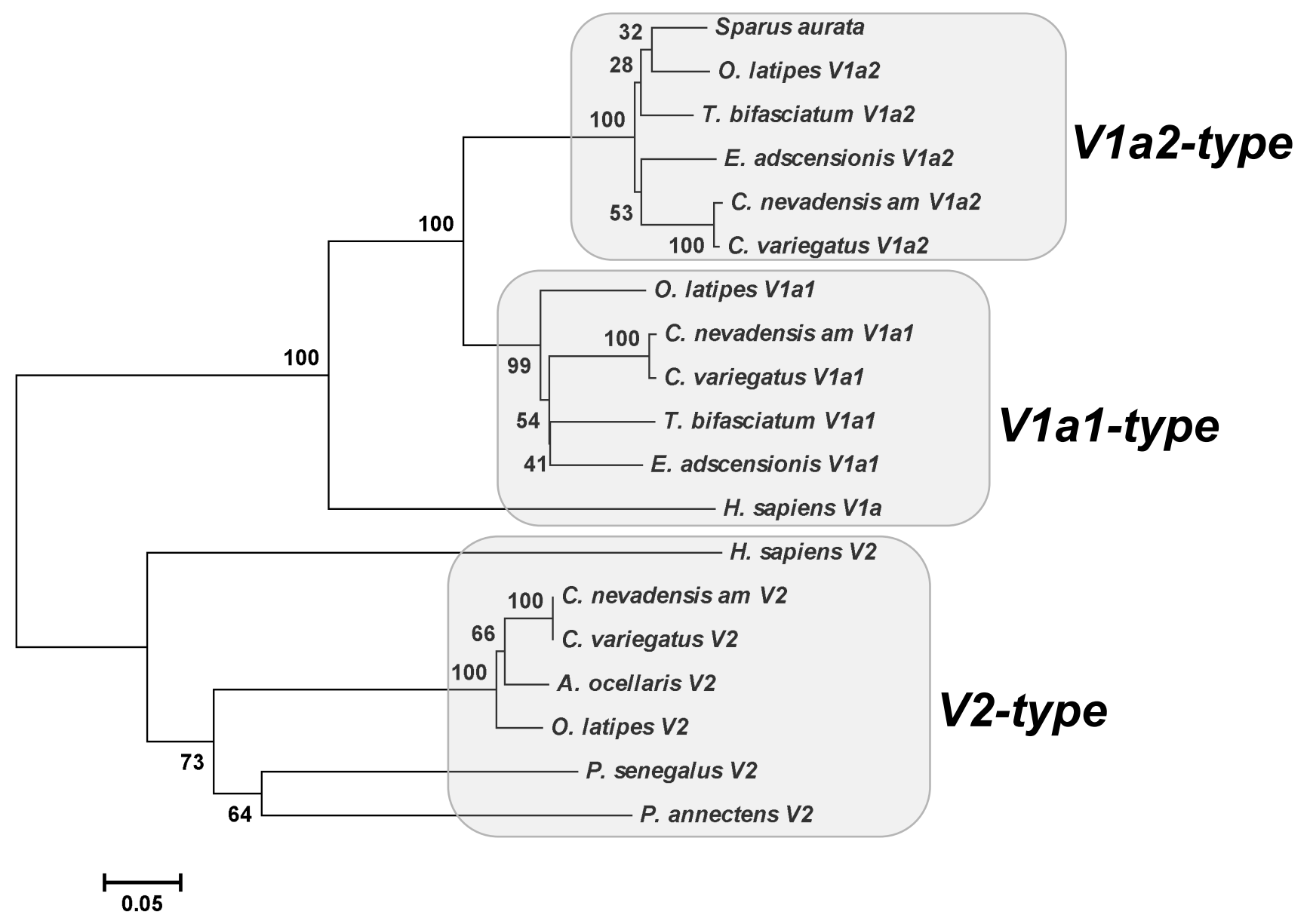


Figure 2. Martos-Sitcha et al.

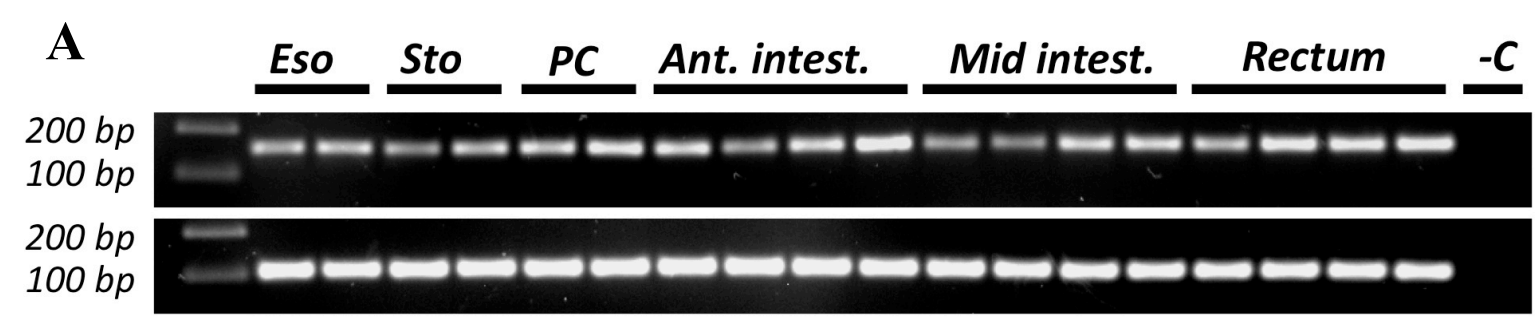

B

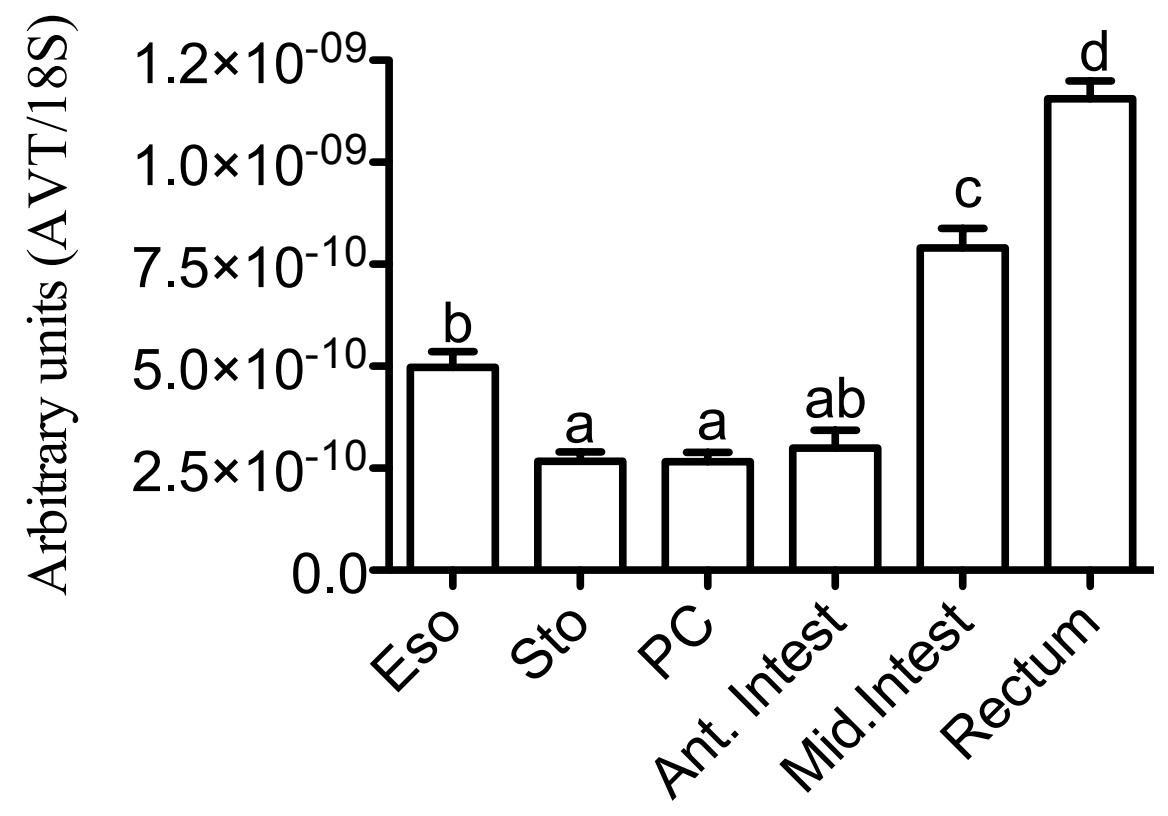


Figure 3. Martos-Sitcha et al.

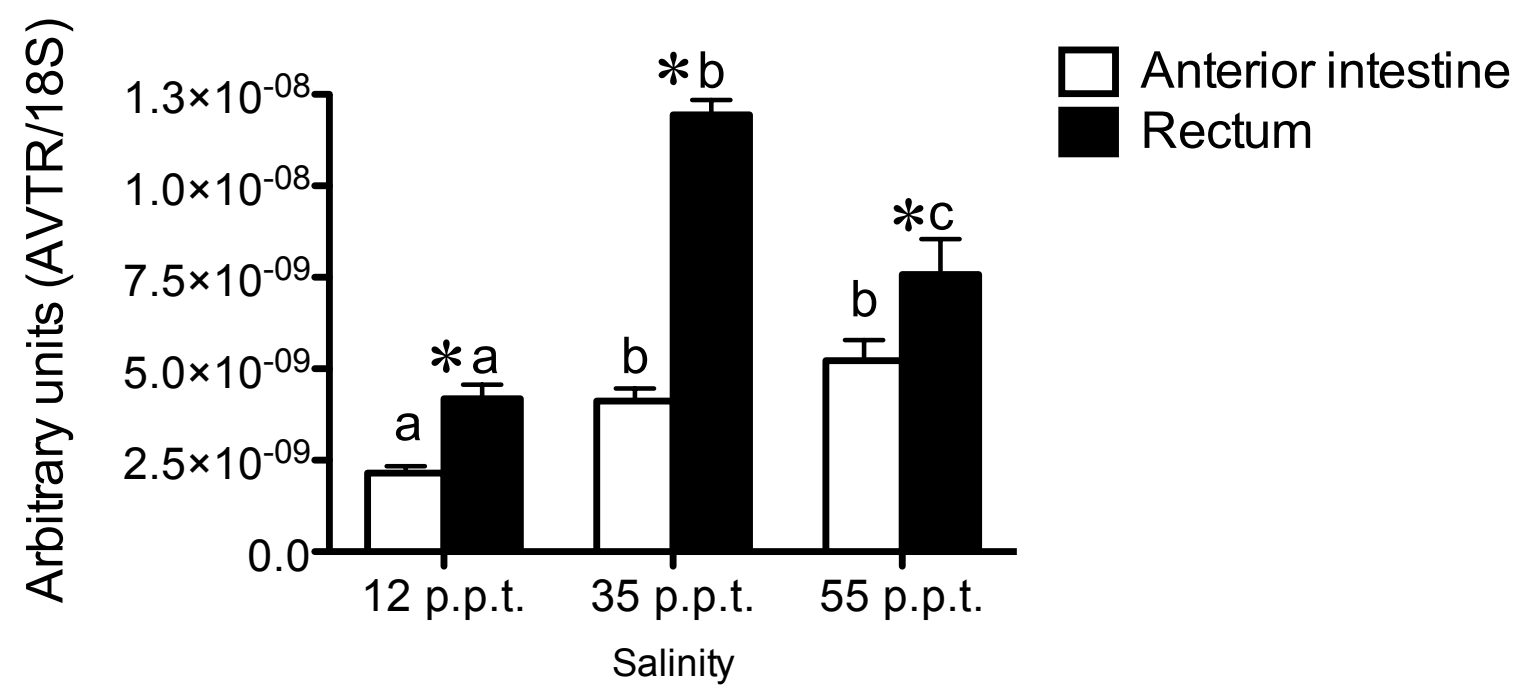


Figure 4. Martos-Sitcha et al.

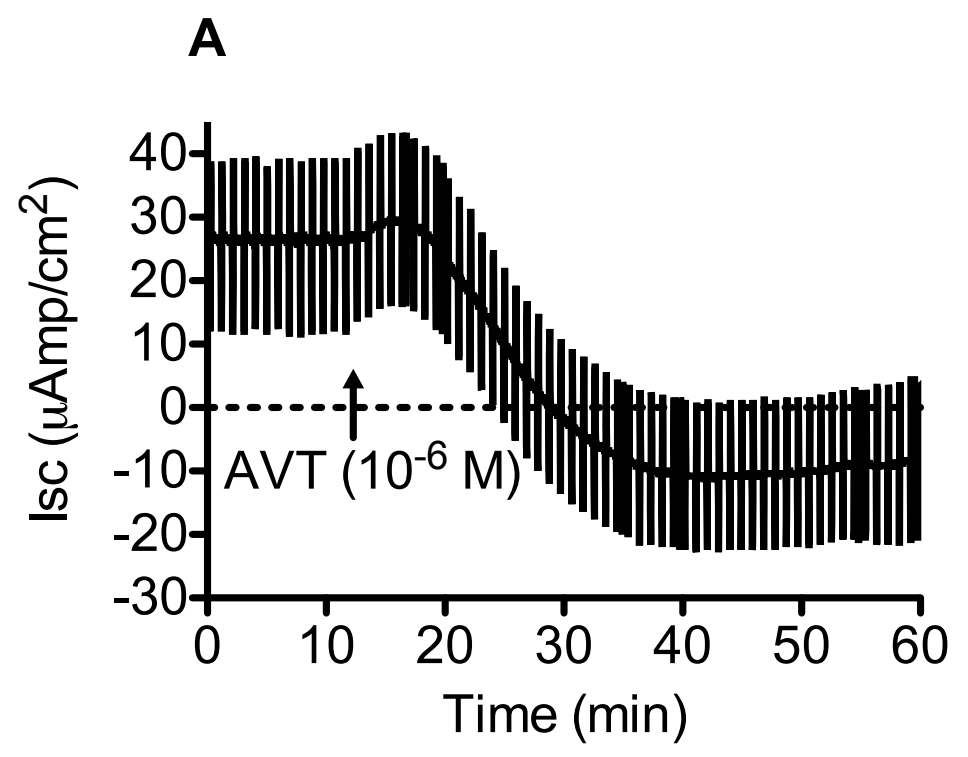

B

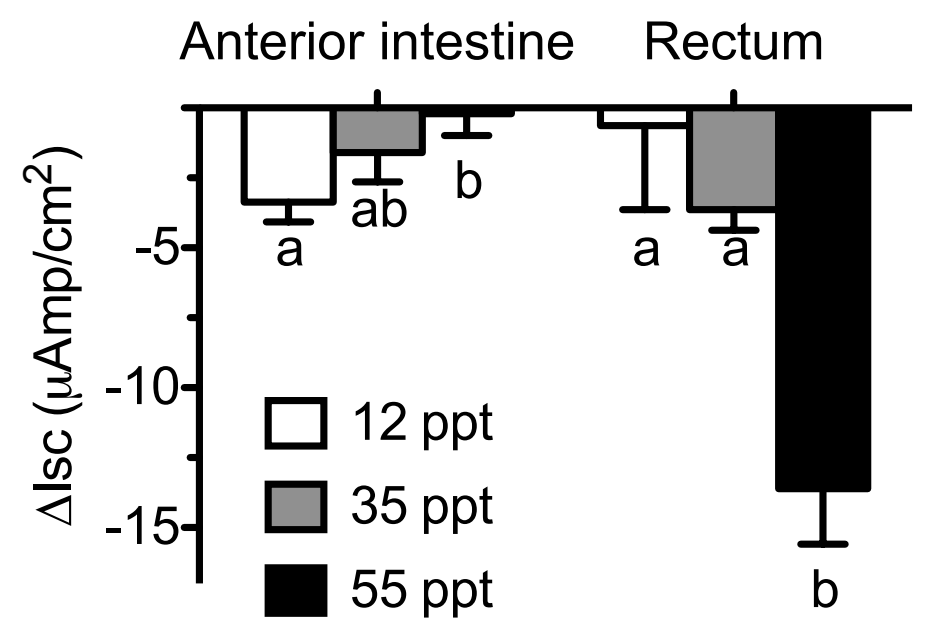


Figure 5. Martos-Sitcha et al.

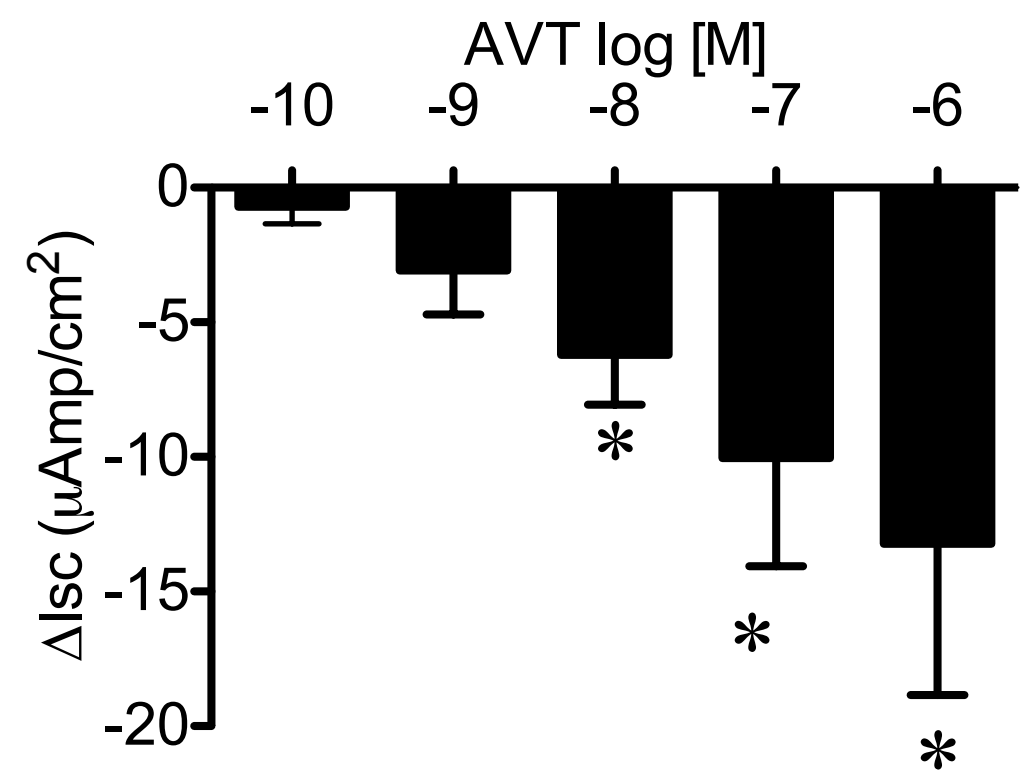


Figure 6. Martos-Sitcha et al.

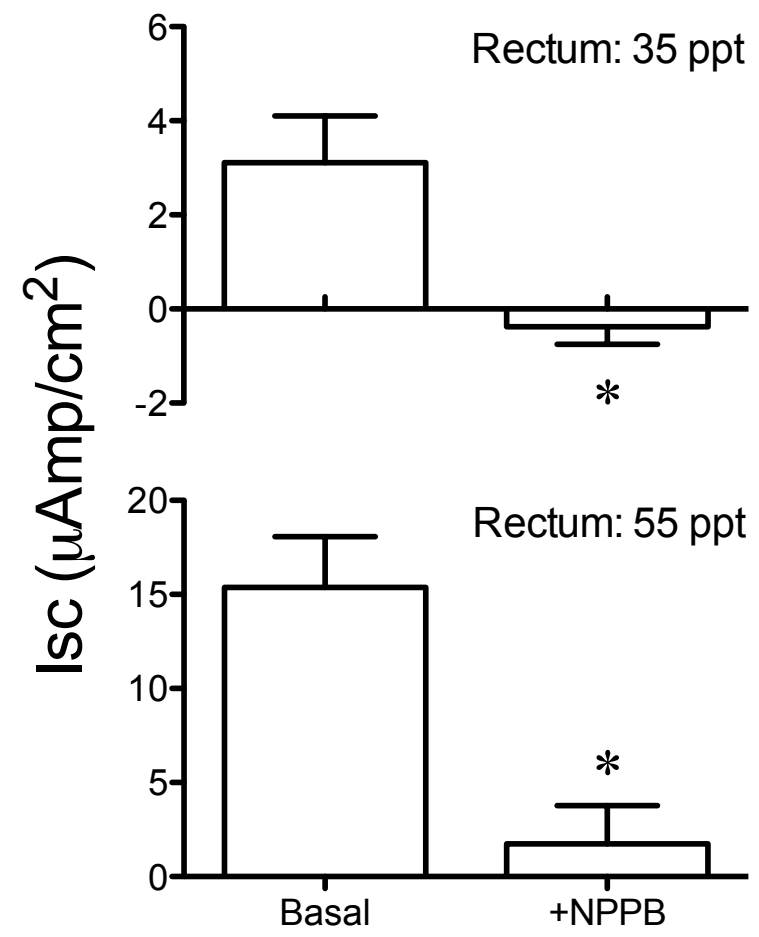


Figure 7. Martos-Sitcha et al.

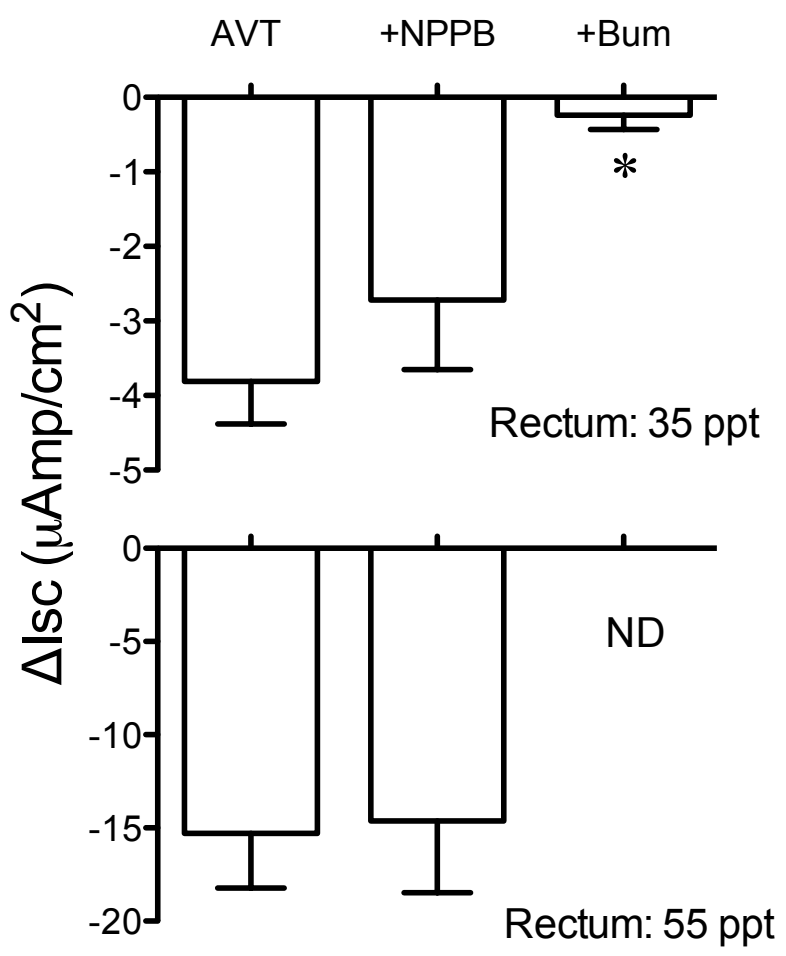

